\title{
The implementation of disaster education after the sixteen years of the 2004 Indian Ocean Tsunami in Aceh-Indonesia: Progress or regress?
}

\author{
Syahrul Ridha ${ }^{1,2,3^{*}}$, Alfi Rahman $^{2,3}$, Abdul Wahab Abdi ${ }^{1}$, Puspita Annaba Kamil ${ }^{4}$ \\ ${ }^{1}$ Department of Geography Education, Universitas Syiah Kuala, Banda Aceh-Indonesia \\ ${ }^{2}$ Pusat Riset Ilmu Sosial dan Budaya (PRISB), Universitas Syiah Kuala, Banda Aceh-Indonesia \\ ${ }^{3}$ Tsunami and Disaster Mitigation Research Center (TDMRC), Universitas Syiah Kuala, Banda Aceh-Indonesia \\ ${ }^{4}$ Department of Geography Education, STKIP Al-Washliyah, Banda Aceh-Indonesia
}

\begin{abstract}
Strengthening disaster education for the community is an effort to build awareness, knowledge, and actions that need to be taken before, during, and after a disaster. Disaster risk communication plays an important role in disaster education as an effort to provide views about disasters to the community. This study aims to look at the progress of the implementation of disaster education school-based after the 2004 Indian Ocean tsunami. Progress is assessed through two aspects, namely: (1) the national curriculum in education unit level, namely Elementary Schools; Junior High School; and Senior High Schools, and (2) the implementation of disaster education school-based in the learning process. The national curriculum will synthesize by using a comprehensive literature review in national curriculum documents. This study applied a content analysis method in analyzing the qualitative data. The questionnaire survey was conducted at (Sekolah Siaga Bencana, SSB) in two districts affected by the 2004 tsunami. A literature study on the national curriculum documents in schools shows that disaster education has been integrated into the curriculum; for example, learning in elementary schools uses a thematic learning approach following factual conditions in the field, such as learning related to disasters. In junior high schools, the curriculum is integrated in an integrated manner in social science learning to provide awareness and knowledge about disasters. Meanwhile, the high school curriculum is integrated into geography subjects to increase knowledge and skills about disasters and make decisions before, during, and after a disaster occurs. This progress has occurred since the change in the curriculum from the KTSP curriculum (2006-2012) to the National Curriculum (2013). However, there are still several obstacles in implementing disaster education in Aceh, such as a lack of facilities for disaster learning. Therefore, a synergy between the government and schools is needed to improve disaster education school-based implementation within the national curriculum.
\end{abstract}

\section{Introduction}

Increased attention to disasters is caused by awareness of disaster hazards. The danger of disasters is a part of human life that cannot be predicted when, where, and how big the impact will be. The character of a disaster is described as an event that produces an impact on the community to produce a response to the incident. The development of disaster knowledge has shaped people's perceptions of disasters; even until now, disasters are understood as unpredictable events.

Strengthening disaster education for the community is an effort to provide awareness and knowledge of disasters and the actions that need to be taken before, during, and after disasters occur [1,2]. Communicating disaster risk plays an important role in disaster education as an effort to provide views about disasters to the community [3]. Increased attention to disasters is caused by the awareness of the dangers of disasters that can be communicated in people's lives, which often cannot be predicted when, where, and how big the impact will be [4,5].
Currently, disasters are one of the issues that are of concern to the world. It is proven by several international policies that focus on disaster management, which is accompanied by the emergence of institutions that specifically examine disaster issues at the national and international levels. For example, the Tsunami and Disaster Mitigation Research Center (TDMRC) was established by Universitas Syiah Kuala after the 2004 Indian Ocean tsunami disaster. In addition, the International Research Institute of Disaster Science (IRIDeS) was established by Tohoku University after the great earthquake and tsunami disaster. East Japan in 2011. After the 2004 Indian Ocean tsunami, Aceh experienced a great downturn in the fields of economy, infrastructure, health, and even education [6]. With national and international assistance, the Acehnese people continue to strive to rise from adversity.

After sixteen years of the tsunami disaster, there have been many developments felt by the people of Aceh, one of which is disaster education. In the national curriculum, disaster education is one of the materials studied in high school [7,8]. Disaster material is studied in class XI in ge-

${ }^{*}$ Corresponding author: syahrul.ridha@unsyiah.ac.id 
ography. The competencies expected in this disaster material consist of two, namely, knowledge competencies and skills competencies. Knowledge competence expects students to be able to analyze the types and management of natural disasters through education, local wisdom, and the use of modern technology, while the competency skills are to make sketches, plans, and/or maps of potential disasters in the local area as well as disaster mitigation strategies based on these maps [9]. Thus, disaster education in Indonesia is developing well, and this can be indicated by the integration of disaster education into the national curriculum.

Disaster education in schools aimed at young children is important in disaster management, and they have a future that is important to save and for better disaster management $[5,1]$. Along with the advancement of science and technology, there is an increasing understanding of the community that disasters can be reduced so that they need to be managed properly. In addition, disaster education has also been studied in various disciplines, such as disaster risk management and environmental studies, but disaster education is a new question in the world of education, and the literature on the concept of disaster education in education is still minimal. [10]. Therefore, this study intends to look at the progress or setbacks of the implementation of disaster education after the 2004 Indian Ocean tsunami. Progress and setbacks are assessed from two aspects of education, namely: (1) the national curriculum in elementary schools; Junior high school; and Senior High Schools, and (2) Implementation in learning in schools.

\section{Method}

The national curriculum is synthesized using a comprehensive literature review in the form of national curriculum documents, namely: elementary school, junior high school, and high school curriculum. During the literature review, this study applied the content analysis method to analyze the qualitative data collected. Meanwhile, the implementation of strengthening disaster education in the teaching and learning process in schools was carried out between July 2019 to March 2020 through a questionnaire service involving 40 Disaster Preparedness Schools (SSB) that had been established and developed by the Tsunami and Disaster Mitigation Research Center (TDMRC) of Universitas Syiah Kuala consisting of teachers and students. The questionnaire survey was conducted in two areas where the Disaster Preparedness School was badly affected by the 2004 tsunami. Descriptive statistics were used to further analyze responses and interviews from teachers and students.

\section{Result and discussion}

\subsection{National curriculum}

\subsubsection{Elementary school national curriculum}

The literature study of the national curriculum document in schools shows that disaster education is integrated into the curriculum; for example, learning in elementary schools uses a thematic learning approach according to factual conditions in the field, such as learning related to disasters. Students are expected to have competencies that can preserve the environment wisely and responsibly. These competencies are applied through the scope of material for connectivity between spaces and tackling environmental problems wisely in life [11]. Thus disaster education can be applied in basic education by providing factual, conceptual, procedural, and metacognitive knowledge at the basic level regarding disaster science, disaster technology, art, and culture for disaster preparedness, and being able to relate the above knowledge in one's context, family, school, community, and natural environment [12].

\subsubsection{Junior high school national curriculum}

In junior high school, the curriculum is integrated in an integrated manner in social science learning to provide awareness and knowledge about the disaster. Students are expected to have competence about the concept of space (location, distribution, potential, climate, morphology, geology, environment) and interactions between spaces and their influence on human life in the aspect of disaster risk reduction [9]. In addition, students are expected to understand spatial aspects and inter-space connectivity in regional and national scopes on the changes and sustainability of post-disaster community life that can affect geographical, economic, and cultural conditions [11]. Various initiatives can be carried out by the school community, either directly or indirectly, and contribute to strengthening disaster preparedness capacity. As a social subsystem that is inseparable from society, schools have the potential to play an active role as the main actor in building the response and preparedness of young people to disasters through disaster education in junior high schools [13].

\subsubsection{High school national curriculum}

Meanwhile, the high school curriculum is integrated into geography subjects to improve knowledge and skills about disasters and the ability to make decisions before, during, and after disasters occur $[2,14]$. While in other subjects, it does not contain disaster material. In addition, there are no specific subjects related to increasing disaster knowledge and skills. This progress has occurred since the curriculum change from the Education Unit Level Curriculum (KTSP) in 2006-2012 to the 2013 National Curriculum. The standard of learning content related to disaster education in geography learning is that students understand and can implement disaster mitigation and adaptation [11]. In addition, the basic competence of disaster knowledge is that students can analyze the types and management of natural disasters through education, local wisdom, and the use of modern technology. In addition to knowledge, students are also expected to have skills in making sketches, plans, and/or maps of potential local disasters and disaster mitigation strategies based on these maps [9]. 
If studied geologically, climatologically, and socioculturally, Aceh Province is an area prone to disasters, both natural and social disasters. It is necessary to plan, integrate, direct, coordinate a sustainable disaster education to provide knowledge to the public about hazards and disaster risk reduction through disaster education. The principles of implementing disaster education are:

- Disaster education for all students regardless of gender, ethnicity, religion, race, and descent.

- Disaster education is held at all types and levels of education.

- Disaster education is carried out in a directed, planned, programmed, integrated, coordinated, professional, and comprehensive manner.

- Disaster education is based on Islamic values and other religious values adopted by the Indonesian people by upholding human rights, customs, and local wisdom.

- The implementation of disaster education is carried out in an integrated manner between lines, types, and levels of education.

- The implementation of disaster education in the formal, non-formal, and informal education channels is carried out by adjusting the time, place, learning facilities, and infrastructure, educators and education staff, forms, other learning resource programs with the conditions of student difficulties.

\subsection{Implementation in learning at school}

The implementation of disaster education in schools is based on lesson hours in each education unit, namely elementary schools, junior high schools, and high schools. In addition, the implementation is also carried out separately as extracurricular learning in disaster-prepared schools $(S B B)[15,16]$. However, there are still some obstacles in implementing disaster education in Aceh, such as the lack of facilities for disaster learning. This is indicated by the absence of a disaster laboratory, fewer study hours. In addition, teachers in schools are less able to use effective learning time due to a lack of training in disaster education learning in schools.

The role of knowledge in disaster education is the basis or beginning of the actions and awareness of each individual $[17,18]$. The existence of knowledge capacity can be used as the basis for each individual in taking action before, during, and after a disaster occurs $[19,20]$. In disaster management, individual or community knowledge is crucial to disaster preparedness $[21,22]$. In disaster preparedness planning, it is necessary to know in advance the types of hazards that occur in an area, for example, geological hazards such as volcanic eruptions; tsunamis; earthquakes, environmental hazards such as forest fires; floods; landslides; and storms [23,2].

When disaster is discussed in the context of geography, it cannot be separated from the concepts of physical and human geography, especially when analyzing disasters where nature and culture are strong factors (Fig.1). Such an integrative approach that considers the reciprocal interaction between nature and culture can solve problems, especially in environmental problems that can be implied in education [23]. In addition to knowing the disaster hazard, it is also necessary to know the causes, vulnerabilities, community resilience, duration, and area of the disaster [24,25]. Therefore, government policies, emergency planning, warning systems, and resource mobilization are the main things to deal with these disasters $[15,5]$.

Disaster preparedness education can be implemented through various types of education, both formal, non-formal, and informal [10]. Disaster preparedness education can be implemented by integrating it into the existing learning curriculum in schools. The objectives of disaster education in Aceh-Indonesia are as follows [5].

- Cultivate human values and attitudes as well as concern for disaster risk.

- Develop an understanding of disaster risk, social vulnerability, physical vulnerability, behavioral vulnerability, and motivation.

- Develop attitudes and improve knowledge, skills for disaster risk reduction, responsible natural resource and environmental management, and adaptation to disaster risk.

- Develop efforts for individual and collective disaster risk reduction.

- Improve disaster preparedness knowledge and skills.

- Improve disaster emergency response capacity.

- Develop readiness for rehabilitation and reconstruction after a disaster occurs.

- Improving individual and family disaster preparedness when a disaster occurs.
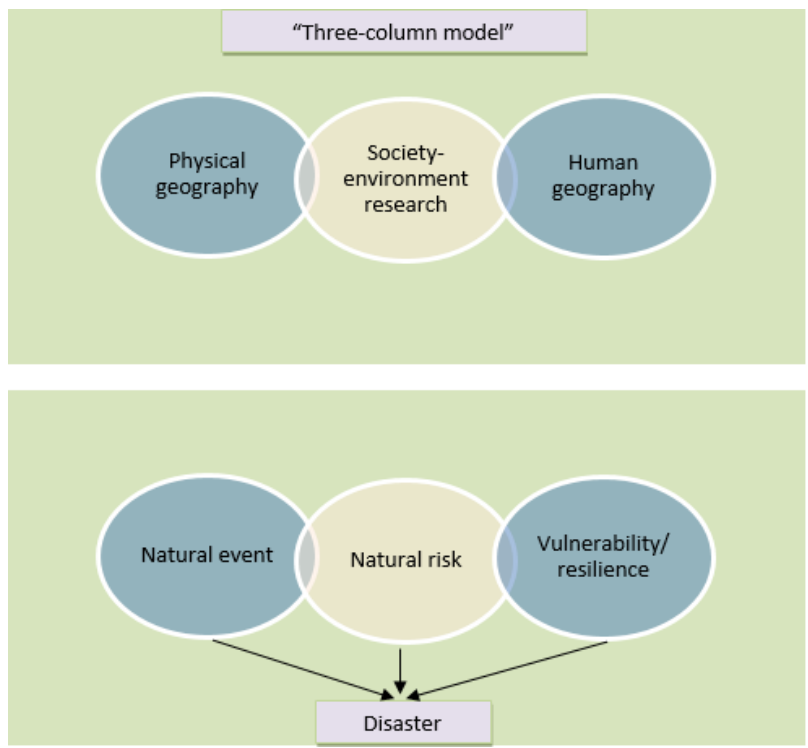

Fig. 1. Three-column model and object of investigation in disaster studies, adapted of [23].

The implementation of education must be adjusted to the characteristics and needs of schools and regions [20]. In practice, schools can collaborate with the government and research institutions at universities nationally and internationally. For example, the establishment of the TDMRC at Universitas Syiah Kuala, the IRIDeS at Tohoku University. So that the goals of disaster education can be achieved optimally to prepare a young generation 
that is strong, intelligent, creative, and innovative in disaster risk reduction, basic education related to disasters can be provided in the context of the implementation of disaster management, including the following [5].

- Knowledge of the type, source, magnitude, impact, and signs of disaster hazard.

- Access for all school components to increase knowledge capacity, understanding, and preparedness skills that can be obtained through the provision of materials, assignments, training, and extracurricular activities.

- Knowledge of the history of disasters that have occurred in their environment or area.

- Knowledge of the vulnerabilities and capacities of the surrounding environment.

- Knowledge of what can be done to minimize the impact of disasters.

- Skills provision for all components in carrying out disaster risk reduction efforts.

- Knowledge of local wisdom for disaster risk reduction.

\section{Conclusions}

The explanation above shows that there has been progress in disaster education in Aceh after the 2004 Indian Ocean tsunami. This is indicated by national curriculum documents, both at the primary and secondary education levels. Students are expected to have attitudes, knowledge, and skills in dealing with disasters before, during, and after disasters occur in the curriculum. Disaster learning can be done intracurricular, extracurricular, and co-curricular. In addition, disaster education in Aceh with the aim of (1) having faith and piety to Allah Subhanahu Wa Ta'ala, (2) having noble character, (3) having knowledge of disaster, (4) having attitude and concern for disaster risk, (5) disaster response and preparedness (6) can adapt to major and sudden changes. However, the implementation of disaster education in both intracurricular, extracurricular, and cocurricular learning has not been optimally implemented, especially in extracurricular and co-curricular learning experiences. Therefore, a synergy between the government and schools is needed to improve the disaster learning experience in schools following the objectives of the national curriculum, both intracurricular, extracurricular, and co-curricular. For example, making a disaster science project competition among students at school is expected to be held in the Aceh tsunami commemoration.

\section{References}

1. P. A. Kamil, S. Utaya, Sumarmi, and D. H. Utomo, Int. J. Disaster Risk Reduct. 43, 101411 (2020)

2. P. A. Kamil, S. Utaya, Sumarmi, D. H. Utomo, A. W. Abdi, and S. Ridha, IOP Conf. Ser. Earth Environ. Sci. 630, 012018 (2021)

3. A. Rahman and K. Munadi, IOP Conf. Ser. Earth Environ. Sci. 273, 012040 (2019)

4. W. Adiyoso and H. Kanegae, in Disaster Risk Reduct. Indones. Prog. Chall. Issues, edited by R. Djalante, M. Garschagen, F. Thomalla, and R. Shaw
(Springer International Publishing, Cham, 2017), pp. 561-587

5. W. Adiyoso, Manajemen Bencana Pengantar Dan Isu-Isu Strategis (Bumi Aksara, Jakarta, 2018)

6. N. Ismail, K. Okazaki, C. Ochiai, and G. Fernandez, Int. J. Disaster Risk Reduct. 28, 439 (2018)

7. S. Ridha, S. Utaya, S. Bachri, and B. Handoyo, IOP Conf. Ser. Earth Environ. Sci. 273, 012035 (2019)

8. S. Ridha, S. Utaya, S. Bachri, B. Handoyo, P. A. Kamil, and A. W. Abdi, IOP Conf. Ser. Earth Environ. Sci. 630, 012017 (2021)

9. Permendikbud RI No. 24, (2016)

10. K. Kitagawa, Educ. Sci. 11, 1 (2021)

11. Permendikbud RI No. 21, (2016)

12. Permendikbud RI No. 20, (2016)

13. P. A. Kamil, S. Utaya, Sumarmi, and D. H. Utomo, IOP Conf. Ser. Earth Environ. Sci. 412, 012016 (2020)

14. S. Ridha and P. A. Kamil, J. Geogr. 120, 72 (2021)

15. R. S. Oktari, K. Shiwaku, K. Munadi, Syamsidik, and R. Shaw, Int. J. Disaster Risk Reduct. 12, 300 (2015)

16. R. S. Oktari, K. Shiwaku, K. Munadi, Syamsidik, and R. Shaw, Int. J. Disaster Risk Reduct. 29, 3 (2018)

17. S. Fuhrmann, L. D. Stone, M. C. Casey, M. D. Curtis, A. L. Doyle, B. D. Earle, D. D. Jones, P. Rodriguez, and S. M. Schermerhorn, J. Geogr. 107, 112 (2008)

18. A. Gampell, J. C. Gaillard, M. Parsons, and L. Le Dé, J. Geogr. 1 (2020)

19. S. Adella, M. Fauzan Nur, N. Nisa, A. Tirtana Putra, F. Rizki Ramadhana, F. Maiyani, K. Munadi, and A. Rahman, IOP Conf. Ser. Earth Environ. Sci. 273, 1 (2019)

20. T. H. Setiawan, G. H. Salim, M. Wimala, A. F. Van Roy, and Y. L. D. Adianto, Int. J. Disaster Manag. 3, 53 (2020)

21. K. Brundiers, Int. J. Disaster Risk Reduct. 27, 406 (2018)

22. A. Gampell, J. Gaillard, M. Parsons, and L. L. Dé, Aust. J. Emerg. Manag. 35, 44 (2020)

23. L. Mönter and K.-H. Otto, J. Geogr. High. Educ. 42, 205 (2018)

24. F. I. Rivera and N. Kapucu, Disaster Vulnerability, Hazards and Resilience: Perspectives from Florida (Springer International Publishing, Switzerland, 2015)

25. K. Kitagawa, Nat. Hazards 105, 3099 (2021) 